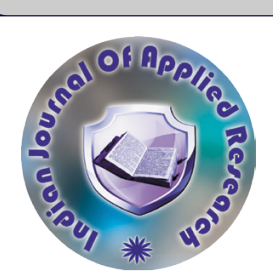

Keerthana. $\mathbf{K}^{*}$
Public Health

\title{
KNOWLEDGE, ATTITUDE, AND PRACTICE OF VACCINATION AMONG PARENTS IN AN INDIAN RURAL COMMUNITY
}

\section{Dr. Suja M. K.}

MSW Student, Department of Social Work, Amrita School of Engineering, Coimbatore Amrita Vishwa Vidyapeetham, India. *Corresponding Author

Associate Professor \& Chairperson, Department of Social Work, Amrita School of Engineering, Coimbatore, Amrita Vishwa Vidyapeetham, India.

This study focuses on the knowledge, attitude and practice of vaccination among parents in an Indian rural community. The researcher was used descriptive research and survey design for the study. The universe of the research was total number of parents in malappuram district. The researcher used purposive sampling as sampling method. Sample size was 102 . The researcher used semi structured survey design for collecting data. It includes; Socio- Demographic Profile of the respondents and semi structured questionnaire includes knowledge, attitude and practice of the respondents regarding vaccination .The study-findings reveals that there are vaccination campaigns and anti-vaccination campaigns are conducting in malappuram district. The parents are aware about vaccination, even though most of them are not ready to practice it.

\section{KEYWORDS : Knowledge, Attitude, Practice, Vaccination, Rural Community, India}

\section{INTRODUCTION}

Many diseases that once caused widespread illness, disability, and death now can be prevented through the use of vaccines. All countries in the world have an immunization programme to deliver selected vaccines to the target group. India is one among the first few countries adopted national immunization programme. After a long interval diphtheria disease is re emerged in malappuram district and it is a challenge to the well known kerala health care model. Malappuram has over the years witnessed a rise in anti-vaccination campaigns.Antivaccination lobby is very strong in the district. They spread fake news regarding vaccines in social media. As a result of this false propagation, many people believe that vaccination will reduce the fertility rate and thereby decrease the population growth. Certain religious believes are also supporting the anti vaccination campaigns. The knowledge, attitude and practice of parents towards vaccination is very important for the successful implementation of vaccination programme.

\section{Purpose Of Vaccination}

Vaccines are medicines which contains live or killed microbes. When vaccines are administered, immune system will respond to that and produce antibodies (this will weaken or kill the disease causing microbes.). When the person later exposed to the same organism that were in the vaccine, these antibodies will recognize organism and fight against that. Children need to be vaccinated as per the schedule from the birth itself. hepatitis B, diphtheria, tetanus, pertussis (whooping cough), measles, mumps, rubella (German measles), varicella (chickenpox), polio, pneumococcus and Haemophilus influenzae type $\mathrm{b}$ (Hib disease, a major cause of spinal meningitis) and, in some states, hepatitis A these are the common vaccine preventable diseases.

\section{Vaccination Coverage In India}

As per National Family Health Survey Report/Fact Sheet there are only 62 percentages of the children are fully vaccinated in all over India in the year 2016 .

\section{Vaccination In Malappuram}

In malappuram district nearly 2.3 lakh children in the group of $0-6$ years were found to be unimmunized or partially immunized.

In 2000 malappuram had reported a case of acute poliomyelitis. Diphtheria cases also reported in the district in 2016 and 2017 Malappuram has over the years witnessed a rise in anti-vaccination campaigns, with fingers having been pointed at religious organizations for spreading false information. According to the Kerala Health Ministry, $90 \%$ of children aged between one and 16 have been immunized in the state. However, the immunization rate dips when it comes to Malappuram, with only $35 \%$ of children aged between one and five and $20 \%$ between seven and 16 being immunized. There is lots of stigma and religious believes associated with vaccination. If large number of children are not vaccinated, there is a high chance for an epidemic break out. There are lots of religious believes associated with vaccination in this Muslim dominated district. And there are not many studies related to this topic. Hence the researcher felt that the study is important in the present scenario.

\section{Research Methodology}

The research work aimed to study the knowledge, attitude and practice of vaccination among parents in an Indian rural community. The Objectives of the study were to understand the socio-demographic profile of parents in a rural community, to assess the knowledge, attitude, and practice regarding vaccination among parents in a rural community, to find out socio-demographic factors has influence on vaccination.

In the present study the researcher selected descriptive research and survey design. And the researcher describes variables such as socio demographic profile of the respondents, Knowledge, attitude and practice of the respondents regarding vaccination. A semi structured questionnaire was used to collect the data. The researcher included the variables such as gender, age, mother tongue, religion, educational status, occupational status, and marital status, number of children, family pattern, and monthly income of the respondents. And also included knowledge, attitude and practice questionnaire. Pilot study was done during the month of September 2017. In order to find out the validity of the questionnaire (semi-structured) Pre-test was conducted with 5 respondents. In this study the universe is the total number of the parents in malappuram district. The total population of malappuram district is 1,698,645 and the exact count of number of parents is not available. Hence the universe is indefinite. In this study the researcher selected 102 respondents (parents of children who are supposed to take vaccination) from 5 panchayaths (mankada,moorkkanad, puzhakkattiri, kodur and pookkottur, panchayats) by using purposive Sampling method.

The Criteria for Selection of Respondents was that the respondents must be the parents of children who are supposed to take vaccination, The age group of the children should be $0-12$ years Data analysis was done by, the collected data were coded and separate code numbers were assigned to each response of each question in the questionnaire, then put it on the coding sheet. These coded data was calculated, tabulated and presented in the form of tables. Simple percentage and chi square test were done using SPSS (Statistical package for social sciences)

\section{RESULTS AND DISCUSSIONS}

\section{Socio-demographic Profile}

Majority of the respondents (73 percent) are female .Majority of the respondents (51 percent) are aged from 29 to 38 years. All respondent's mother tongue is Malayalam. Majority of the respondents ( 69 percent) are Muslims. 47 percent of the respondents completed plus two. Majority of the respondents (46 percent) are jobless. Majority of the respondents (97 percent) are married. Majority of the respondents (64 percent) have 2 to 5 children. Majority of the respondents ( 60 percent) have 1 to 5 members in their family. Majority of the respondents (62 percent) belongs to nuclear family. Majority of the respondents (41 
percent) disagree with confused about scheduling of vaccination.

\section{KAPstudy on vaccination}

\section{Knowledge Of Vaccination}

40percent of the respondents agree that it is important to vaccinate children. Majority of the respondents (57 percent) disagree with more than one vaccine at the same time have no negative impact on child. Majority of the respondents (54 percent) agree with vaccines prepare the body to fight against disease without exposing the symptoms. Majority of the respondents (63 percent) agree with vaccines work against viruses and bacteria. Majority of the respondents (54 percent) agree with immune system can't handle so many vaccines. Majority of the respondents (51 percent) strongly agree with it is recommended to vaccinate children against seasonal influenza. Majority of the respondents ( 51 percent) disagree with vaccines have aborted fetal tissue. Majority of the respondents (59 percent) agree with child cannot be vaccinated in case of high grade fever or undergoing medical treatment. Majority of the respondents (62 percent) agree with redness and tenderness at the injection site, mild fever, and pain are common side effects of vaccination. Majority of the respondents (57 percent) of the respondents disagree with all children from 9 months to less than 15 years of age should be given measles- rubella vaccination (MR). Majority of the respondents ( 55 percent) agree with vaccines are not adequately tested for safety. Majority of the respondents (44 percent) disagree with breastfeeding is a substitute of vaccination. Majority of the respondents (62 percent) disagree with vaccines produced from dog and pig cells. Majority of the respondents (53 percent) agree with it is recommends a 3 month deferral of pregnancy after MMR vaccination is needed. Majority of the respondents(57 percent) agree with BCG,OPVand Hepatitis B are administered during birth.

\section{Attitude on vaccination}

40 percent of the respondents agree with vaccination is important. Majority of the respondents (52 percent) agree with politicians should be the role models for vaccination. Majority of the respondents (53 percent) disagree with there could be a link between MMR vaccination and autism. 43 percent of the respondents disagree with the worry about the possible side effects of vaccination. Majority of the respondents ( 55 percent) disagree with media reports on vaccination encourages to vaccinate their child. Majority of the respondents (61 percent) agree with media exaggerate reports about disease outbreak and vaccination. 42 percent of the respondents disagree with vaccination is important for boys than girls. Majority of the respondents ( 51 percent) agree with vaccination must give according to schedule. Majority of the respondents ( 54 percent) disagree with vaccination increases mortality rate, 42 percent of the respondents are agree with vaccination have severe side effects. 44 percent of the respondents are agree with vaccination is safe and effective for prevention of diseases. Majority of the respondents( 63 percent) agree with MR vaccination reduces the fertility rate. Majority of the respondents( 62 percent) agree with social media discourages to vaccinate child. Majority of the respondents( 65 percent) disagree with child immunization is prohibited in religion. Majority of the respondents( 59 percent) agree with natural immunity is better than vaccine acquired immunity

\section{Practice of vaccination.}

47 percent of the respondents are disagreeing with receiving vaccination for their child. 49 percent of the respondents are disagreeing with recommending others to vaccinate their children. Majority of the respondents (55 percent) agree with anti-vaccination groups. 40 percent of the respondents agree with drug companies are making more profit from vaccination. Majority of the respondents (56 percent) agree with hepatitis vaccine should be given as soon as practicable after birth. Majority of the respondents (60 percent) agree with anti-vaccination campaign is focusing on the welfare of the community. Majority of the respondents (59 percent) disagree with attended anti-vaccination campaign. Majority of the respondents (57 percent) disagree with using internet for clarification of doubts regarding vaccination. Majority of the respondents (56 percent) disagree with they knows someone who had a serious reaction to vaccination. Majority of the respondents (64 percent) are disagree with feel social pressure to vaccinate their child,. 45 percent of the respondents agree with they know someone who does not take vaccine because of religious or cultural reasons. Majority of the respondents( 67 percent) agree with health care professionals recommended to vaccinate, Majority of the respondents( 52 percent) agree with there are other ways to prevent diseases, Majority of the respondents( 47
Majority of the respondents (48 percent) disagree with most of the people that they know are vaccinating their children.

\section{Factors affecting the key variables (chi square test)}

There is a significant relationship between educational status and practice (infant received vaccines according to ministry of health schedule.)There is a significant relationship between educational status and practice (drug companies are making more profit.)

\section{CONCLUSION}

Implications for Social Work Practice: In malappuram district, as per the immunization campaign the health workers are conducting various awareness programmes. These programmes are aimed to reduce the stigma associated with vaccination and increase the vaccination status of the district. As a result of these programmes knowledge of the parents regarding vaccination has improved. The anti-vaccine lobby has been very strong in the district. They spread messages against vaccination on WhatsApp and Facebook timelines. Many uneducated users believe that it is the fact and they are also spreading the same messages. Many people believe that vaccines affect the fertility of their children when they grow up. Not only is that, a number of Muslim management schools also not willing to give vaccination to the students.

Along with this there are someone called naturalist, who are opposed to vaccines and any form of modern medicine. They are also spreading messages against vaccination. In these situation social workers has a big role in educating the community about the importance of vaccination. They can conduct awareness programmes against antivaccination campaigns. Educate the parents regarding the advantages of vaccination, Conduct awareness programmes with the help of religious leaders and health professionals. And also further research can be done in this area.

\section{REFERENCES:}

1) Ammar Ihsan Awadh,corresponding author Mohamed Azmi Hassali, Omer Qutaiba Allela, Siti Halimah Bux, Ramadan M Elkalmi, and Hazrina Hadi (2014) "Immunization knowledge and practice among Malaysian parents a questionnaire development and pilot-testing"2014; 14: 1107

2) AngadiM.M, Arun Pulikkottil Jose, Rekha Udgiri, K.A. Masali, (2013) "A Study of Knowledge, Attitude and Practices on Immunization of Children in Urban Slums of Bijapur City, Karnataka, India" 7(12): 2803-2806.

3) Astha Agrawal, (2016), "To study the Knowledge regarding immunization schedule among parents and the source of information regarding vaccination" Vol 3, No 12

4) Bryan J. Vonasek, Francis Bajunirwe, Laura E. Jacobson, Leonidas Twesigye, James Dahm, Monica J. Grant, Ajay K. Sethi ( 2016 ) "Do Maternal Knowledge and Attitudes towards Childhood Immunizations in Rural Uganda Correlate with Complete Childhood Vaccination"

5) Chris-Otubor, G.O.Dangiwa, D.A , L.D,Anukam, N.C (2012) Assessment of Knowledge, Attitudes and Practices of Mothers In Jos North Regarding Knowledge, Attitudes and Practices of
Immunization Volume 5, Issue 6, PP. 34-45

6) Dharmalingam.A. Raghupathy N. S Sowmiya.M, D. Amudharaj H. M. Jehangir (2017) "Immunization knowledge, attitude and practice among mothers of children from 0 to 5 years" Dharmalingam A et al. Int J Contemp Pediatr. ; 4(3): 783-789

7) Heba Adel Ramadan, Sahar Mohamed Soliman, Rabab Gad Abd El-kader ( 2016) Knowledge, Attitude and Practice of Mothers toward Children's Obligatory Vaccination Volume 5, Issue 4 Ver. II, PP 22-28

8) Ibrahim H Al-Ayed( 2012)" Knowledge and practices of childhood immunization among primary health care providers in Riyadh City"

9) Ibrahim H Al-Ayed, and Shaffi Sheik,(2006 )"knowledge and practices of childhood immunisation among primary health care providers in riyad city." 13(1): 19-24

10) Jolsna Joseph, Vijayalakshmi Devarashetty, S. Narayana Reddy, M. Sushma (2015) Parents' knowledge, attitude, and practice on childhood immunization, Vol 4 , Issue 6

11) Kio JO, Agbede CO, Mkpuruoma EJ (2016) Knowledge Beliefs and Practices Regarding Immunization among Nursing Mothers in Nigeria Vol 24

12) Mabrouka A.M. Bofarraj Omar Al-Moukhtar University-Al-Beida, Libya. (2008) Knowledge, attitude and practices of mothers regarding immunization of infants and preschool children at Al-Beida City, Libya 9(1):29-34.

13) Mabrouka AM Bofarraj (2008) Knowledge, attitude and practices of mothers regarding immunization of infants and preschool children at Al-Beida City, Libya. Vol 9, No 1

14) Mereena MS, ,Mrs.Sujatha.R, (2014),"A Study on Knowledge and Attitude Regarding Vaccines among Mothers of Under Five Children attending Pediatric OPD in a Selected Hospital at Mangalore" Volume 3, Issue 5 Ver. III PP 39-46

15) Nisar N, Mirza M, Qadri MH( 2010). Knowledge, Attitude and Practices of mothers regarding immunization of one year old child at Mawatch Goth, Kemari Town, Karachi. Pak J Med Sci;26(1):183-186

16) Priyesh Marskole, Ritesh Rawat, Priyanka Chouhan, Priyanka Sahu, Rahul choudhari Gajara Raja Medical College, Gwalior, Madhya Pradesh, India (2016) "Knowledge, Attitude, and Practices on Vaccination among Mothers of under-5 children, Attending Immunization Out Patients Department at Gwalior, Madhya Pradesh"

17) Roos M. Bernsen, Fatmah R. Al-Zahmi Noura A. Al-Ali, Rowayah O. Hamoudi, (2011) "Knowledge, Attitude and Practice towards Immunizations among Mothers in a Traditional City in the United Arab Emirates" 4(3): 114-121

18) Samah Omar Alfahl and Khulood Mohammed Alharbi (2017) Parents' Knowledge, Attitude and Practice towards Childhood Vaccination, AlMadinah, Saudi Arabia Volume 3 Issue 1

19) Satish gupte The short textbook of medical microbiology(including parasitology) tenth edition, jaypee publications, New delhi, 2010 page.no:83-91

20) Shiferaw Birhanu, Aderaw Anteneh, Yezabnesh Kibie, Ayalew Jejaw (January 2016) Knowledge, Attitude and Practice of Mothers Towards Immunization of Infants in

21) Sylvia E. Caingles, MD, Joanne J. Lobo, M.D (2011) survey on the knowledge, 

attitude,and practices of parents in barangay district regarding their children's immunization Vol 12 No.1

22) Waris Qidwai, Syed Sohail Ali, Semi Ayub, Salma Ayub Yousif MA, Ahmed Abdulrahman Albarraq, Mustafa Awad A Abdallah and Abubaker Ibrahim Elbur (2013) "Parents' Knowledge and Attitudes on Childhood Immunization, Taif, Saudi Arabia ",Volume 5. Issue 1 